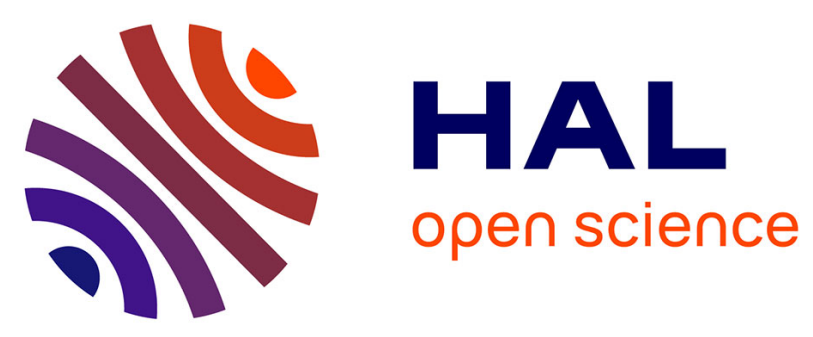

\title{
Does disaster affect immigrant victims more than non-immigrant victims in Dutch general practice: a matched cohort study
}

Rik J. H. Soeteman, C. Joris Yzermans, Peter M. M. Spreeuwenberg, Tina Dorn, Jan J. Kerssens, Wil J. H. M. Bosch, Jouke Zee

\section{To cite this version:}

Rik J. H. Soeteman, C. Joris Yzermans, Peter M. M. Spreeuwenberg, Tina Dorn, Jan J. Kerssens, et al.. Does disaster affect immigrant victims more than non-immigrant victims in Dutch general practice: a matched cohort study. Journal of Public Health, 2008, 17 (1), pp.27-32. 10.1007/s10389-008-0197-6 . hal-00478178

\section{HAL Id: hal-00478178 https://hal.science/hal-00478178}

Submitted on 30 Apr 2010

HAL is a multi-disciplinary open access archive for the deposit and dissemination of scientific research documents, whether they are published or not. The documents may come from teaching and research institutions in France or abroad, or from public or private research centers.
L'archive ouverte pluridisciplinaire HAL, est destinée au dépôt et à la diffusion de documents scientifiques de niveau recherche, publiés ou non, émanant des établissements d'enseignement et de recherche français ou étrangers, des laboratoires publics ou privés. 


\title{
Does disaster affect immigrant victims more than non-immigrant victims in Dutch general practice: a matched cohort study
}

\author{
Rik J. H. Soeteman • C. Joris Yzermans • \\ Peter M. M. Spreeuwenberg • Tina Dorn • \\ Jan J. Kerssens • Wil J. H. M. van den Bosch • \\ Jouke van der Zee
}

Received: 5 December 2007 / Accepted: 24 April 2008 / Published online: 10 June 2008

(C) Springer-Verlag 2008

\begin{abstract}
Background In the literature, immigrant victims appear to be more vulnerable to health effects of a disaster than indigenous victims. Most of these studies were performed without pre-disaster measurement and without using a control group.

Aim The objective of the study is to monitor differences between two groups of victims, Turkish immigrants and indigenous Dutch, in utilization and morbidity as presented in general practice after a man-made disaster.

Methods A matched cohort study was performed with predisaster (1 year) and post-disaster (4 years) measurements of patients from 30 general practices in Enschede. Turkish victims $(\mathrm{N}=303)$ and Dutch victims $(\mathrm{N}=606)$, matched on age, gender and socioeconomic status, were included. Main outcome measures were psychological problems and physical symptoms as recorded by the general practitioner, using the International Classification of Primary Care (ICPC).

Results The Turkish victims showed higher utilization than the Dutch victims prior to the disaster. In the 1st postdisaster year, both groups of victims showed an increase in
\end{abstract}

R. J. H. Soeteman $(\bowtie) \cdot$ C. J. Yzermans $(\bowtie) \cdot$

P. M. M. Spreeuwenberg • T. Dorn · J. J. Kerssens · J. van der Zee

NIVEL, Netherlands Institute for Health Services Research,

P.O. Box 1568, 3500 BN Utrecht, The Netherlands

e-mail: soetwaay@xs4all.nl

e-mail: j.yzermans@nivel.nl

W. J. H. M. van den Bosch

Department of General Practice,

University Medical Centre St Radboud,

P.O. Box 9101, 6500HB Nijmegen, The Netherlands utilization, but the increases did not differ significantly. The Turkish group showed no significantly greater increase than the Dutch group in the five most prevalent clusters of health problems (psychological, respiratory, skin, musculoskeletal, and digestive).

Conclusion The Turkish victims in general practice were as vulnerable as the Dutch victims for the effects on their health of this man-made disaster. Differences between Turkish and native Dutch victims of this man-made disaster can largely be explained by the differences that existed already before the disaster.

Keywords Disasters · Ethnicity · Morbidity . Longitudinal studies $\cdot$ General practice

\section{Introduction}

Turkish migrants first arrived in the Netherlands in the 1960 s, and a new generation settled in later decades in order to reunite with their compatriots. They had lived in a rural area and entered a country with a different culture and habits while they were separated from their families at home. In general, they performed unskilled jobs that were rejected by the native Dutch population.

This study monitored the impact of a major disaster on the health of this migrant group, an important minority in the city. The disaster took place on 13 May 2000 in the city of Enschede, which is located in the Eastern part of the Netherlands. A fireworks depot situated in a residential neighbourhood exploded on that day, killing 18 residents and 4 fire-fighters and injuring around 1,000 other people. Some 1,200 victims, one-third of them with Turkish 
backgrounds, lost their homes and had to be relocated for a long period. A total of approximately 12,000 peopleresidents, passers-by, and rescue workers-were affected by the disaster.

The present study examined the health problems of Turkish victims on the basis of the electronic medical records (EMRs) kept by general practitioners (GPs). Turkish immigrants in the Netherlands are known to have higher utilization rates of general practice than the native population (Deville et al. 2006; Stronks et al. 2001; Uiters et al. 2006), and they present more digestive, eye, musculoskeletal, respiratory, and skin problems than the indigenous Dutch inhabitants (Weide and Foets 1998). In addition, they more often present with psychological problems (Weide and Foets 1998; van der Linden et al. 2004).

In a Dutch interview-based study, primary findings with Turkish immigrants were that need and predisposing factors as mental and physical health and sociodemographic characteristics predicted health care consumption (Kamperman et al. 2007). Moreover, migrant specific factors were found among these Turkish immigrants. If the acculturation process (integration of its own culture and the new one of the host country) was not successful, specific characteristics (being insecure about its own cultural roots, no social relations with Dutch people) were associated with the presence of mental disorders.

The disaster literature shows that ethnic minority groups have been described with higher rates of post-disaster mental health problems than other groups (Norris et al. 2002; Bolin and Klenow 1988; Fothergill et al. 1999; Galea et al. 2004; Garrison et al. 1995; La Greca et al. 1998; Lonigan et al. 1991; Perilla et al. 2002). However, these studies did not make use of pre-disaster assessments. It has therefore been unclear, whether post-disaster health differences between immigrant and non-immigrant groups can be attributed to the disaster experience or already existed before the event.

The current population-based study offered a unique opportunity of studying the health of the Turkish disaster victims. They could be followed prior to and following the disaster due to the circumstance that general practitioner records already were operational before the disaster occurred. As a consequence, pre-disaster baseline data on health were available, and pre-post comparisons could be made. The objective of this study was to examine whether Turkish victims presented stronger increases of GP utilization and health problems following this disaster than indigenous Dutch victims.

The research questions of the present study were:

1. Do Turkish and Dutch victims present increases of contacts in general practice services in a period following the Enschede fireworks disaster and do they present more problems and symptoms?

2. Do Turkish victims demonstrate greater increases in contacts in general practice services and in presenting problems and symptoms than Dutch victims?

\section{Methodology}

General practitioners

In the Netherlands, every citizen is registered with one GP, who acts as a gatekeeper to secondary care. As a result, victims of this disaster and their medical histories were already known to their GPs in the period prior to the disaster, and it was possible to collect data for this study relating to 1 year prior to the disaster. All GPs participating in the study were already using a computerized information system.

All 60 GPs in the town of Enschede were invited to participate, and 44 of them agreed to do so. The 16 GPs who did not participate gave three different reasons; 6 expected an increase in workload, 9 had no victims in their practices, and 1 did not use an electronic data system.

\section{Patients}

Persons were marked as victims in their GPs' patient registers by the zip code of their home at the disaster date and when they were registered in the database of the municipal Information and Advice Center (IAC). At the IAC, people were registered as victims on the basis of the municipal identity register or when they considered themselves victims. They all received a research number (barcode), through which they could be monitored anonymously in the GPs' database. Victims' immigrant status was documented at the IAC. The victims were registered as being Turkish whenever they had been born in Turkey or one or both parents had been born there. Victims were excluded (for both groups) if they belonged to other immigrant groups than the Turkish. Victims of all ages were included in the study, but they had to be registered with their GP's practice during the entire study period from 13 May 1999 until 13 May 2004.

People in the Netherlands with lower or middle incomes, $64 \%$ of the general population (van der Linden et al. 2004), were covered by a public health insurance scheme until 2006. The fact that the type of insurance was recorded in the GPs' patient records provided us with a crude indicator of socioeconomic status (SES). We matched for the characteristics of age, gender, and insurance type. A minimum of two Dutch victims was required for each Turkish victim, in order 
to create an appropriate availability of matches on all three covariates. Finally, 303 Turkish victims (and 606 Dutch ones) were included and monitored for 5 years.

Patients were informed about their GPs' participation in this study by posters and leaflets in the waiting room and could object to the use of their anonymized data (but nobody did). Data collection was performed in accordance with the privacy protection procedures of the Dutch data protection authority (Roorda et al. 2004).

\section{Procedures}

Dutch general practitioners use the International Classification of Primary Care (Lamberts and Wood 1987), a multiaxial classification system that allows registering diagnoses as well as problems and symptoms.

Symptoms and diagnoses recorded during patient contacts were extracted for the purposes of this study and were grouped in clusters, the psychological, respiratory, skin, musculoskeletal, and digestive clusters. These clusters were organ-based and were known to be the most prevalent (Weide and Foets 1998; van der Linden et al. 2004).

\section{Statistical analysis}

The study period started 1 year before the disaster occurred and lasted 4 years post-disaster. Demographic data on the two victim groups were compared using chi-square tests. Utilization was calculated on an annual basis as the mean number of contacts (face to face and by telephone). The model compared differences in prevalence rates of each post-disaster year compared with the pre-disaster baseline year. The prevalence rates for health problems in the six most prevalent clusters were calculated as the percentage of victims, Turkish and Dutch, visiting their GP for those health problems at least once in a 1-year period.

The data were analyzed using a multilevel model for repeated measurements (level 1, measurement occasion; level 2, person; level 3, general practice). In the random part, the influence of the GPs was modeled as one overall between GP variance at the highest level. At the level below that, i.e., the person level, the error variance for each occasion was modeled together with all the co-variances between the occasions, which controls for the autocorrelation between measurement occasions within persons. In the fixed part, five measurement occasion intercepts were estimated for both groups. The three control covariates (age, gender, insurance) were also modeled as fixed effects and centered around their means.

A Poisson regression model was used for utilization. The models for morbidity were suitable as logistic models. All analyses were performed with MLWIN2.02, using penalized quasi-likelihood (PQL) with second order and an extra dispersion parameter. Contrasts with a Wald test were used to test the hypothesis that prevalence rates and utilization observed in Turkish victims increased by a higher rate than in Dutch victims.

\section{Results}

The Turkish immigrant group and the Dutch group were equal regarding socio-demographic factors (Table 1).

Turkish victims had higher pre-disaster utilization than Dutch victims, and both groups of victims showed significant increases during the 1 st year post-disaster $(\mathrm{P}<$ 0.001 , Table 2). The utilization in both groups in the $2 \mathrm{nd}$, $3 \mathrm{rd}$ and 4 th years was higher than pre-disaster, but the increase seen in Turkish victims in the 2 nd and 4 th years post-disaster was not significantly greater than the increase observed in Dutch victims. This means that the disaster had an equal impact on both groups.

Both groups of victims displayed significant postdisaster increases of psychological problems $(\mathrm{P}<0.001$, Table 3 ) in all 4 years, with a peak in the 1 st year. But when these increases observed in Dutch victims and in Turkish victims were compared to each other, no significant differences were found again. In the year prior to the disaster, Turkish victims presented fewer psychological problems than the Dutch victims.

After the disaster had occurred, the Turkish victims showed two changes in the physical symptoms that were presented to the GP. One concerned a significant decrease in respiratory symptoms in the 1 st year post-disaster as compared with the pre-disaster year. This deviation from the pre-disaster baseline differed significantly from the increase found in Dutch victims $(\mathrm{P}<0.05)$. In addition, a significant increase in musculoskeletal symptoms was seen in Turkish victims during the 1st post-disaster year, although this increase was not significantly larger when compared with the increase of the Dutch victims. No significant post-disaster increases were found for symptoms

Table 1 Characteristics of victims registered on their GP's list between May 1999 and May 2004

\begin{tabular}{lll}
\hline Groups of patients & Dutch N=606 & Turkish N=303 \\
\hline \% Male & 51.2 & 51.2 \\
Mean age in years & 29.9 & 29.6 \\
\% low/middle SES & 91.7 & 91.7 \\
\% forced relocation & 24.8 & 27.7 \\
\% no contact & 2.6 & 1.3
\end{tabular}

SES $=$ Socioeconomic status, as indicated by insurance type No contact $=$ did not contact GP during study period 
Table 2 Utilization rate by Dutch and Turkish victims as mean number of contacts with GPs per year, from 1 year pre-disaster until 4 years post-disaster (years 1 through 4 )

\begin{tabular}{lllll}
\hline Utilization & & Dutch & Turkish & $\begin{array}{l}\text { P-value Turkish } \\
\text { vs. Dutch }\end{array}$ \\
\hline Pre-disaster & Year 0 & 3.5 & 5.6 & \\
Post-disaster & Year 1 & $4.1^{* * *}$ & $6.8^{* * *}$ & 0.752 \\
& Year 2 & $4.1^{* *}$ & 6.2 & 0.502 \\
& Year 3 & $4.1^{* *}$ & $6.6^{* *}$ & 1 \\
& Year 4 & $4.0^{*}$ & 6.2 & 0.59 \\
\hline
\end{tabular}

${ }^{*} \mathrm{P}<0.05$, year compared with year 0

${ }^{*} * \mathrm{P}<0.01$, year compared with year 0

${ }^{* * *} \mathrm{P}<0.001$, year compared with year 0

of the digestive system and the skin for either of the groups. In the pre-disaster year, Turkish victims showed a higher extent of all symptoms than the Dutch.

\section{Discussion}

The aim of our study was to explore whether victims of Turkish background had more GP contacts and presented significantly more health problems in the aftermath of a man-made disaster than native Dutch victims. We considered the number of contacts in general practice, psychological problems, and physical symptoms as outcome measurements; all related to their pre-disaster baseline levels. The post-disaster increases on utilization of general practice services and on psychological problems and physical symptoms were comparable in Turkish and in Dutch victims, whereas the Turkish had higher levels than the Dutch prior to and following the disaster. The finding of an equivalent association between experiencing the disaster and health problems between immigrants and indigenous contradicts the conclusions of many studies (Bolin and Klenow 1988; Galea et al. 2004; Garrison et al. 1995; Lonigan et al. 1991; Perilla et al. 2002; Drogendijk et al. 2003), which demonstrated that ethnic minority groups were more at risk of psychological problems. The question, however, is how to explain this finding? A major methodological difference between these studies and the present one is that they did not use a pre-disaster measurement. In our study, we had baseline pre-disaster data to our disposal in a prospective design. If we had commenced our analysis after the disaster, we would quickly have assumed that the disaster had a greater effect on the Turkish victims than on the Dutch victims, an erroneous conclusion easily drawn from crosssectional results.

In this study, we demonstrated stronger increases of GP utilization and psychological problems for both victim groups than in another, shorter-term study on the same
Table 3 Prevalence rates (\%) of psychological problems, respiratory, skin, musculoskeletal, and digestive symptoms in Dutch and Turkish victims attending their GP at least once per year, from 1 year predisaster (year 0) until 4 years post-disaster (years 1 through 4)

\begin{tabular}{|c|c|c|c|c|}
\hline \multicolumn{2}{|l|}{ Psychological } & \multirow{2}{*}{$\begin{array}{l}\text { Dutch } \\
21.0\end{array}$} & \multirow{2}{*}{$\begin{array}{l}\text { Turkish } \\
12.4\end{array}$} & \multirow[t]{2}{*}{$\begin{array}{l}\text { P-value Turkish } \\
\text { vs. Dutch }\end{array}$} \\
\hline Pre-disaster & Year 0 & & & \\
\hline Post-disaster & Year 1 & $57.1^{* * *}$ & $41.7^{* * *}$ & 1 \\
\hline & Year 2 & $39.3^{* * *}$ & $24.7^{* * *}$ & 0.823 \\
\hline & Year 3 & $46.5^{* * *}$ & $25.5^{* * *}$ & 0.173 \\
\hline & Year 4 & $37.9^{* * *}$ & $20.0^{* * *}$ & 0.247 \\
\hline \multicolumn{5}{|l|}{ Respiratory } \\
\hline Pre-disaster & Year 0 & 17.8 & 27.9 & \\
\hline \multirow[t]{4}{*}{ Post-disaster } & Year 1 & 18.2 & $20.7^{*}$ & $0.048 \S$ \\
\hline & Year 2 & 19.4 & 26.5 & 0.406 \\
\hline & Year 3 & 16.2 & 24.8 & 0.841 \\
\hline & Year 4 & 16.1 & 23.4 & 0.624 \\
\hline \multicolumn{5}{|l|}{ Skin } \\
\hline Pre-disaster & Year 0 & 18.5 & 21.8 & \\
\hline \multirow[t]{4}{*}{ Post-disaster } & Year 1 & 14.8 & 19.8 & 0.532 \\
\hline & Year 2 & 18.5 & 23.7 & 0.617 \\
\hline & Year 3 & 16.3 & 25.0 & 0.162 \\
\hline & Year 4 & 18.3 & 21.4 & 1 \\
\hline \multicolumn{5}{|c|}{ Musculoskeletal } \\
\hline Pre-disaster & Year 0 & 19.8 & 31.2 & \\
\hline \multirow[t]{4}{*}{ Post-disaster } & Year 1 & 22.7 & $38.7^{*}$ & 0.442 \\
\hline & Year 2 & 21.9 & 30.5 & 0.439 \\
\hline & Year 3 & 19.8 & 33.2 & 0.663 \\
\hline & Year 4 & 18.1 & 26.8 & 0.617 \\
\hline \multicolumn{5}{|l|}{ Digestive } \\
\hline Pre-disaster & Year 0 & 12.1 & 23.2 & \\
\hline \multirow[t]{4}{*}{ Post-disaster } & Year 1 & 11.8 & 29.5 & 0.119 \\
\hline & Year 2 & 11.8 & 25.1 & 0.584 \\
\hline & Year 3 & 11.1 & 26.6 & 0.267 \\
\hline & Year 4 & 13.8 & 25.4 & 0.888 \\
\hline
\end{tabular}

$* \mathrm{P}<0.05$, year compared with year 0

$* * \mathrm{P}<0.01$, year compared with year 0

$* * * \mathrm{P}<0.001$, year compared with year 0

$\S \mathrm{P}<0.05$, Turkish compared with Dutch

disaster (Soeteman et al. 2006), which may be explained by the fact that the mean age of the victims in our study was 10 years younger. Younger disaster victims are generally more vulnerable than elderly victims, as stated by Norris in her review (Norris et al. 2002). An explanation for this finding may be 'the inoculation theory': when people get older they become more experienced and have better skills to cope with unexpected life events (Ferraro 2003; Knight et al. 2000; Norris and Murrell 1988; Thompson et al. 1993). On the other hand, in a third study on the fireworks disaster population, which was controlled for pre-disaster utilization, no differences due to (younger) age were found for all victims (Soeteman et al. 2008). The lack of control groups of unaffected Dutch and Turkish patients in the 
current study should be noted in this context too. This was due to the immigrant status being just a variable with the IAC data and not present in the EMR of the GPs, so that we were unable to relate utilization and morbidity to the natural development of "normal" immigrants in general practice acting as controls. Moreover, it should be mentioned that the number of contacts in general practice in the Netherlands had increased throughout the study period (Verheij et al. 2006), matching the increase seen in the Dutch and Turkish victims studied here. Therefore, the supposed longlasting increased prevalence rates in our study run parallel with this increase in Dutch general practice. In this context, we have to be thoughtful about the time span of disasterrelated health effects of our study.

The significant decrease in respiratory symptoms in Turkish victims in the first post-disaster year may be related with the finding that the Turkish already had a high predisaster level of these symptoms, higher than the Dutch victims. However, respiratory symptoms were not found among the health effects of large-scale earthquakes on Turkish victims (Basoglu et al. 2002; Basoglu et al. 2004; Kilic and Ulusoy 2003; Livanou et al. 2002; Tural et al. 2004). Only one disaster study on Turkish victims found "trouble in getting breath" as a somatisation symptom (Karanci and Rustemli 1995), and we may not conclude, therefore, that the decrease in respiratory symptoms was culturally influenced, since so little is known about this as a disaster-related finding. The significant decrease in the Turkish victims is a remarkable finding, nevertheless.

The higher level of utilization and extent of physical symptoms in the Turkish victims in the year prior to the disaster was a confirmation of the results of other studies (see Introduction). Some studies suggest an underlying "ethnical factor" (Weide and Foets 1998) as an explanation (genetic factors, specific living and working conditions, the way of presenting problems and doctor-patient communication). Others assume a "condition migrante"(Berry 1994; Knipscheer 2000a), meaning the conflicts of living between two (religious) cultures, social isolation, and being uprooted, the perception of illness, low socioeconomic status, and discrimination. These factors are summarized in the concept of "acculturation": a dynamic competition between two cultures. Studies often point at socioeconomic differences between the immigrant group and the indigenous population (Stronks et al. 2001). Finally, in our study, the extent of predisaster psychological problems of the Turkish victims was lower when compared to the Dutch victims, which is in contradiction to other studies (Weide and Foets 1998; Dirkzwager et al. 2004; van der Linden et al. 2004). We assume that this phenomenon (fewer psychological problems and more physical symptoms) may be interpreted as somatization (Kamperman et al. 2007; Knipscheer 2000b): psychological distress expressed by physical symptoms.

\section{Conclusions}

Although pre-disaster differences exist between victims belonging to the Turkish minority in the Netherlands and ethnic Dutch victims, Turkish disaster victims appear to react as strong as Dutch victims do to a man-made disaster. This idea is supported by one of the participating GPs who, informally, stated the following: "My Turkish patients were already in a bad condition in the period prior to the disaster. They needed more help than the Dutch before the disaster and after it as well." It is obvious that disasters tend to occur more frequently in socially deprived areas (Donker et al. 2002; Rubonis and Bickman 1991). Adverse health outcomes in the aftermath of disasters probably originate in the deprivation pre-disaster.

The results of our study plead for an extra effort in assistance if members belonging to any ethnic minority group present more health problems than native citizens. This will concern the provision of supplemental psychological and social help, including the employment of GPs and supporting personnel. This should have been implemented not only after a disaster (den Ouden et al. 2005), but irrespective of any disaster. In our opinion, this will apply for Turkish immigrants in northwestern Europe, but not for other groups, such as Moroccan immigrants, who present with other utilization patterns and other symptoms and problems (Kamperman et al. 2007; Uiters et al. 2006). The findings of this study demonstrate that general practice can play an important role in detecting health problems presented by both native inhabitants and immigrants prior to and following a disaster. The possibility of retrieving pre-disaster data is a crucial issue in assessing the assumed vulnerability to present health problems of immigrant groups in the aftermath of a disaster.

Acknowledgements We gratefully thank the participating general practitioners for registering all contacts in times of pressure.

This study was funded by a grant obtained from the Ministry of Public Health, Welfare, and Sports in the Netherlands.

Conflict of interest statement The authors disclose any relevant associations that might pose a conflict of interest.

\section{References}

Basoglu M, Salcioglu E, Livanou M (2002) Traumatic stress responses in earthquake survivors in Turkey. J Trauma Stress 15:269-276

Basoglu M, Kilic C, Salcioglu E, Livanou M (2004) Prevalence of posttraumatic stress disorder and comorbid depression in earthquake survivors in Turkey: An epidemiological study. J Trauma Stress 17:133-141

Berry JW (1994) Acculturation and psychological adaptation: an overview. In: Bouvy A (ed) Journeys into cross-cultural psychology. Swets \& Zeitlinger, Amsterdam, pp 129-141 
Bolin R, Klenow DJ (1988) Older people in disaster: a comparison of black and white victims. Int J Aging Hum Dev 26:29-43

den Ouden DJ, Dirkzwager AJ, Yzermans CJ (2005) Health problems presented in general practice by survivors before and after a fireworks disaster: associations with mental health care. Scand J Prim Health Care 23:137-141

Deville WLJM, Uiters E, Westert GP, Groenewegen PP (2006) Perceived health and consultation of GPs among ethnic minorities compared to the general population in the Netherlands. In: Westert GP, Jabaaij L, Schellevis FG (eds) Morbidity, performance and quality in primary care. Dutch general practice on stage. Radcliffe, Oxford, pp 85-96

Dirkzwager AJ, Yzermans CJ, Kessels FJ (2004) Psychological, musculoskeletal, and respiratory problems and sickness absence before and after involvement in a disaster: a longitudinal study among rescue workers. Occup Environ Med 61:870-872

Donker GA, Yzermans CJ, Spreeuwenberg P, van der Zee J (2002) Symptom attribution after a plane crash: comparison between self-reported symptoms and GP records. Br J Gen Pract 52:917922

Drogendijk AN, van der Velden PG, Kleber RJ, Christiaanse BBA, Dorrestein SM, Grievink L, Gersons BPR, Olff M, Meewisse ML (2003) Turkish victims of the Enschede firework disaster: A comparative study (in Dutch). Gedrag en Gezondheid 31:145162

Ferraro FR (2003) Psychological resilience in older adults following the 1997 flood. Clin Gerontol 26:139-143

Fothergill A, Maestas EG, Darlington JD (1999) Race, ethnicity and disasters in the United States: a review of the literature. Disasters 23:156-173

Galea S, Vlahov D, Tracy M, Hoover DR, Resnick H, Kilpatrick D (2004) Hispanic ethnicity and post-traumatic stress disorder after a disaster: evidence from a general population survey after September 11, 2001. Ann Epidemiol 14:520-531

Garrison CZ, Bryant ES, Addy CL, Spurrier PG et al (1995) Posttraumatic stress disorder in adolescents after Hurricane Andrew. J Am Acad Child Adolesc Psych 34:1193-1201

Kamperman AM, Komproe IH, de Jong JT (2007) Migrant mental health: a model for indicators of mental health and health care consumption. Health Psychol 26:96-104

Karanci AN, Rustemli A (1995) Psychological consequences of the 1992 Erzincan (Turkey) earthquake. Disasters 19:8-18

Kilic C, Ulusoy M (2003) Psychological effects of the November 1999 earthquake in Turkey: an epidemiological study. Acta Psychiatr Scand 108:232-238

Knight BG, Gatz M, Heller K, Bengtson VL (2000) Age and emotional response to the Northridge earthquake: a longitudinal analysis. Psychol Aging 15:627-634

Knipscheer JW (2000a) Cultural convergence and divergence in mental health care. Empirical studies on mental distress and help-seeking behaviour of Surinamese, Ghanaian, Turkish an Moroccan migrants in the Netherlands. Universal Press, Veenendaal, pp 1-19

Knipscheer JW (2000b) Cultural convergence and divergence in mental health care. Empirical studies on mental distress and help-seeking behaviour of Surinamese, Ghanaian, Turkish an Moroccan migrants in the Netherlands. Universal Press, Veenendaal, pp 131-152

La Greca AM, Silverman WK, Wasserstein SB (1998) Children's predisaster functioning as a predictor of posttraumatic stress following Hurricane Andrew. J Consult Clin Psychol 66:883-892
Lamberts H, Wood M (1987) International classification of primary care. Oxford University Press, Oxford

Livanou M, Basoglu M, Salcioglu E, Kalendar D (2002) Traumatic stress responses in treatment-seeking earthquake survivors in Turkey. J Nerv Ment Dis 190:816-823

Lonigan CJ, Shannon MP, Finch AJ, Daugherty TK (1991) Children's reactions to a natural disaster: Symptom severity and degree of exposure. Adv Behav Res Ther 13:135-154

Norris FH, Friedman MJ, Watson PJ, Byrne CM, Diaz E, Kaniasty K (2002) 60,000 disaster victims speak: Part I. An empirical review of the empirical literature, 1981-2001. Psychiatry 65:207-239

Norris FH, Murrell SA (1988) Prior experience as a moderator of disaster impact on anxiety symptoms in older adults. Am J Community Psychol 16:665-683

Perilla JL, Norris FH, Lavizzo EA (2002) Ethnicity, culture, and disaster response: identifying and explaining ethnic differences in PTSD six months after Hurricane Andrew. J Soc Clin Psychol 21:20-45

Roorda J, van Stiphout WA, Huijsman-Rubingh RR (2004) Postdisaster health effects: strategies for investigation and data collection. Experiences from the Enschede firework disaster. J Epidemiol Community Health 58:982-987

Rubonis AV, Bickman L (1991) Psychological impairment in the wake of disaster: the disaster-psychopathology relationship. Psychol Bull JID - 0376473 109:384-399

Soeteman RJ, Yzermans CJ, Kerssens JJ, Dirkzwager AJ, Donker GA, van den Bosch WJ, van der ZJ (2006) The course of post-disaster health problems of victims with pre-disaster psychological problems as presented in general practice. Fam Pract 23:378-384

Soeteman RJH, Yzermans CJ, Spreeuwenberg P, Lagro-Janssen TALM, van den Bosch WJHM, van der Zee J (2008) Health problems of women, men and various age groups in family practice after a disaster; a matched cohort study with a predisaster assessment. submitted

Stronks K, Ravelli AC, Reijneveld SA (2001) Immigrants in the Netherlands: equal access for equal needs? J Epidemiol Community Health 55:701-707

Thompson MP, Norris FH, Hanacek B (1993) Age differences in the psychological consequences of Hurricane Hugo. Psychol Aging 8:606-616

Tural U, Coskun B, Onder E, Corapcioglu A, Yildiz M, Kesepara C, Karakaya I, Aydin M, Erol A, Torun F, Aybar G (2004) Psychological consequences of the 1999 earthquake in Turkey. J Trauma Stress 17:451-459

Uiters E, Deville WL, Foets M, Groenewegen PP (2006) Use of health care services by ethnic minorities in The Netherlands: do patterns differ? Eur J Public Health 16:388-393

van der Linden MW, Westert GP, de Bakker DH, Schellevis FG. Symptoms and diseases in the population and in general practice (in Dutch). 2004. NIVEL,Utrecht/RIVM,Bilthoven. Ref Type: Report

Verheij RA, te Brake $\mathrm{H}$, Abrahamse HA, van den Hoogen $\mathrm{H}$, Braspenning J, van Althuis T. Netherlands Information Network of General Practice. Facts and figures about general practitioner care in the Netherlands. http:/www.LINH.nl. 2006. Utrecht/ Nijmegen: NIVEL/WOK, 2006. Visited 2007/03/08

Weide MG, Foets M (1998) Migrants in family practice: their symptoms and diagnoses differ from the Dutch (in Dutch). Ned Tijdschr Geneeskd 142:2105-2109 